\title{
Contexto religioso, social, político y educativo del suR del Perú DURANTE LA LLEGADA DEL ADVENTISMO A INICIOS DEL SIGLO XX SEGÚN LA LITERATURA NO ADVENTISTA
}

\author{
Kebby Rodríguez Gutiérrez* y Glúder Quispe Huanca \\ Universidad Peruana Unión, Lima - Perú \\ Recibido: 27 de mayo de 2017 Aceptado: 20 de junio de 2017
}

\begin{abstract}
Resumen
¿Cómo fue el contexto religioso, social, político y educativo del sur del Perú durante la llegada del adventismo a inicios del siglo XX según la literatura no adventista? Desde sus inicios, el indígena peruano de los andes vivía en un contexto favorable para su desarrollo como cultura y sociedad. Con la llegada de los españoles, cambiaron su realidad religiosa, social, política, educativa y más. Después del establecimiento de la República, el mestizaje perpetuó la sumisión y el abuso. Los primeros intentos de educación al hombre andino por Manuel Zúñiga Camacho, no fue bien recibido por el gamonal, terrateniente, leguleyo y el cura. Con la llegada de la educación adventista, a través de la familia misionera stahl, el indígena halló su progresiva reivindicación en la sociedad.
\end{abstract}

Palabras clave: Indigenismo, educación, religión, política, sociedad, adventismo.

\begin{abstract}
How was the religious, social, political and educational context of southern Peru during the time of Seventh-day Adventism in the early 20th century, according to non-Adventist literature? From its beginnings, the Peruvian indigenous of the Andes lived in a favorable context for its development as culture and society. With the arrival of the Spaniards, they changed their religious, social, political, educational reality and more. After the Republic was established, miscegenation perpetuated submission and abuse. The first attempts of education to the Andean man by Manuel Zúñiga Camacho was not well received by the gamonal, landowner, lawyer and the priest. With the Seventh-day Adventist education, through the Stahl missionary family, the Indian found his progressive claim in society.
\end{abstract}

Keywords: Indigenism, education, religion, politics, society, Seventhday Adventism.

\footnotetext{
*Email: kebby@upeu.edu.pe
} 


\section{Introducción}

La literatura no-adventista peruana, es abundante en contenido y de gran calidad. Hay historiadores, poetas, ensayistas, periodistas, políticos, novelistas, tesistas, entre otros más. Gracias a ellos, los peruanos conservan una historia milenaria, cuyo pasado se remonta a un período incásico imponente. Según José María Arguedas, es "el país de todas las sangres", aquí convergen las más variadas razas del mundo, que dieron inicio a la nación que es hoy.

Tras la conquista española, la del Perú, también fue la historia de los fracasos y la derrota. De la discriminación y el abuso, de la imposición y la fuerza. Solo una pequeña muestra de esto último, es la historia de los indígenas andinos después del coloniaje. Eran abusados de continuo, no hubo descanso en el ultraje del hombre blanco y mestizo hacia el hombre andino. El indio no halló paz ni buscándola en el párroco.

El adventismo, en la forma de misioneros extranjeros, llegó en 1898 al Perú y en 1911 al altiplano. Su presencia influyó en el indígena para bien. Le liberó de sus vicios aprendidos del hombre blanco, le educó con integralidad, le restituyó el cariño hacia la vida y le reivindicó en la sociedad. El propósito de esta investigación es describir el contexto religioso, social, político y educativo del sur del Perú durante la llegada del adventismo a inicios del siglo XX, según la literatura no adventista.

El estudio de estos contextos se dividen en los períodos antes de 1902, (la conquista española, la colonia y la república); luego desde los años 1902 al 1910, cuando empezó el desarrollo de la escuela de Utawilaya de Manuel Zúñiga Camacho; y finalmente, el tercer período, desde 1911 al 1915, que abarca desde la llegada de Fernando Stahl a Puno, hacia el establecimiento de la libertad religiosa en el Perú. 


\section{Contexto Religioso}

\subsection{Antes de 1902}

El indígena concebía el concepto de ayllu como una unidad familiar religiosa. Su percepción respecto a la muerte, fue que ésta es una nueva forma de vida. Para ellos, el ser querido no moría, solo pasaba a una nueva forma de existencia.

Dentro de su concepción de ultratumba, los indígenas les rendían culto a sus antepasados. Es interesante para la investigación notar que estas libaciones estaban íntimamente ligadas a su convivencia en el ayllu.

El dios andino era Wiracocha, a él temían y reverenciaban. Con el transcurrir de los años, estas creencias fueron el fundamento de la religión de los incas. La andina, era una religión totémica, adoraban a Pachamama (la tierra) y Mamakocha (el mar). Entendieron el concepto del bien y el mal, así lo evidenciaron en su comprensión del espíritu maléfico llamado Supay.

A la llegada de los españoles, los indígenas fueron cristianizados por la fuerza, bajo pena de muerte inquisitorial. Solo hubo algunos pequeños grupos, que tuvieron una impresión positiva del culto católico. Vieron entre las esculturas cristianas, a sus propios dioses andinos. Pero éstos eran la excepción, más que la regla.

En el acto de cristianización, había que hacer concesiones, y los indígenas andinos asimilaron las creencias de los cristianos sin abandonar por completo las suyas propias. El catolicismo, casi al unísono, fue considerado por los historiadores como los principales cómplices del abuso de poder que infligían sobre el indígena los gamonales y los terratenientes; el mestizo y el hombre blanco. Fue para finales del siglo XIX que llegaron los primeros cristianos protestantes al Perú. 


\subsection{Entre los años 1902 al 1910}

Habiéndola sincretizado con el catolicismo español por la fuerza, el hombre andino había perdido su antigua religión. De este modo, por ciertas celebraciones religiosas, el sacerdote católico impuso cobros excesivos. El cura se constituyó en un abusador del indio. Estas circunstancias llevaron a los indios andinos a abandonar su poblado en un acto de repudio al cristianismo.

Es notable en esta etapa, la rebeldía indígena. Algo había cambiado en él. Esta vez, se dejaba ver en el hombre andino deseos de liberación. En cuanto a su realidad religiosa, en este período el indígena se preparaba para una posterior serie de insurrecciones de carácter religioso.

\subsection{Entre los años 1911 al 1915}

El indígena siempre fue un hombre de profundas convicciones religiosas. Practicaba una suerte de cristianismo andino que el sacerdote permitía, siempre y cuando permanezca catequizado.

Debido a los excesos cometidos por el clero católico en los andes, los indios aprendieron a ver en el párroco a alguien que debía ser dejado en el olvido. A esta situación se añadió la presencia de los protestantes extranjeros en Perú.

Hubo metodistas y bautistas, pero fueron los adventistas quienes emprendieron la obra evangelística con gran éxito entre los indios de la serranía sureña. A través de la labor misionera de la familia Stahl en 1911 en Platería, el andino encontró en el cristianismo protestante, el bálsamo anhelado durante décadas.

Sin embargo, la herencia totémica andina permanecía inamovible. Hubo indígenas preparados para ser bautizados que todavía creían en la Pachamama. Los adventistas no creen que el sincretismo sea un modo bíblico de evangelización, por lo cual debían ser pacientes en la enseñanza bíblica. 
Los adventistas tuvieron un impacto religioso importante. Como es de esperar, no todos vieron con buenos ojos estas acciones evangelísticas. Pronto, el catolicismo emprendió una campaña proselitista imitando las maneras de los adventistas.

Acompañada de esta recatequización, se sumó una nueva acción propagandista de ataque a la fe protestante. Los cultos de la misa, empezaron a ser usados para calumniar y ridiculizar a los adventistas. Sin embrago, el corazón indígena había sido conquistado. A través del cariño y el respeto a la dignidad andina, los adventistas se abrieron paso creciendo rápidamente entre los pobladores. Los autores citados coinciden en puntualizar que el indígena evangelizado por los adventistas era un hombre nuevo.

\section{Contexto social}

\subsection{Antes de 1902}

Antes de la conquista española, el indio era un hombre independiente, de buenas cualidades. El hombre andino se hacía responsable de sus deberes en el ayllu, él mismo era el constructor de su choza, labrador de su tierra, tejedor de sus muebles y fabricador de su propio traje. En resumen, el hombre andino presentaba todas las cualidades que demanda una vida social organizada.

Aunque todo era muy primitivo, emprendía sus acciones con diligencia y experticia. Para él, el hogar era más que una construcción. Allí crecerían sus hijos y compartiría la vida con su esposa. El indio no era un urbano, más bien, un campesino. A pesar de su naturaleza reflexiva y contemplativa, quizá algo solitaria, el indígena aprendió a vivir en comunidad.

La mujer andina, como corresponde a su actividad femenina, es una dama laboriosa y abnegada. Cocinaba sus alimentos reconociendo su posición en la sociedad como madre y esposa. Atendía a sus hijos con esmero y, si hacía falta, auxiliaba 
al marido en las toscas faenas agrícolas. Como era natural, ella se ganaba el respeto en el ayllu, según su laboriosidad y utilidad en la comunidad.

Después de la conquista española, aparecieron elementos extraños en las tranquilas planicies andinas. La situación de la mujer andina se vio alterada. Entre el hombre andino y el español nunca hubo un vínculo de amistad. De ellos aprendió los vicios que practicaría por más de cuatro siglos. El coloniaje no tuvo piedad con los indígenas.

Desde que el hombre blanco pisó el altiplano, el indígena se tornó malicioso, se había convertido en la sombra de lo que alguna vez fue. El rol del hombre andino en la sociedad se vio rebajado a los niveles más bajos posibles.

Como resultado de las violaciones por los españoles, a la partida del hombre blanco, quedó el mestizo. Quien, a pesar de sus raíces indígenas, simpatizaba más con el español, perpetuando por los siguientes siglos, el abuso y la opresión.

\subsection{Entre los años 1902 al 1910}

En esta etapa, los indígenas del sur del Perú, tuvieron la más denigrante posición social en toda la América indígena. Los autores investigados, concluyen que el hombre andino era visto como la última expresión humana en el Perú. El indígena fue la gran víctima de la discriminación racial y la diferencia de clases del Perú.

La mujer indígena que no permaneciera en su casa, era víctima de violaciones. No suficiente con esto, soportaba el maltrato doméstico en silencio, que el esposo le propinaba en su regreso a casa.

Las humildes chozas eran arrasadas. En Lima, se hicieron esfuerzos académicos por concientizar a la población costera y norteña de la realidad del indígena andino, sin embargo, poco pudieron lograr. Al indígena, no le restó más que su fortaleza y resistencia innatas. 


\subsection{Entre los años 1911 al 1915}

El hombre andino de la segunda década del siglo XX es otra persona. Va reintegrándose en la sociedad con éxito. Ha recobrado su amor propio, aprendió a leer, y su presencia en la sociedad asombra al viajero advenedizo.

Algunos autores citados concuerdan que el hombre andino ha sido regenerado, en gran parte, por el evangelio. Ahora es un hombre alegre en proceso de restauración social.

El único caso en que se da una convivencia, según Luis Valcárcel, entre un blanco y un indio, es con Fernando Stahl y sus estudiantes de Platería.

Debido a esta nueva amistad, le ha acontecido al indígena, una transformación asombrosa. Es un interesante efecto en cadena. Los Stahl discipulan al indígena, y éste ya evangelizado, educa a su prójimo. Así, hermanados nuevamente como cuando el ayllu, empiezan a disfrutar de los privilegios de ser un ciudadano. El indio evangelista había vuelto a la sociedad reivindicado.

\section{Contexto político}

\subsection{Antes de 1902}

En cuanto a lo político, la moral incaica estaba regida por preceptos simples, de penalizaciones ejemplarizadoras. En claro contraste, la región que habitaba el hombre andino en el período de la República, tenía una forma de gobierno muy inestable e incapaz de actuar con justicia.

Políticamente hablando, el indígena era un hombre sin derechos. El hombre blanco se constituyó en su principal insaciable explotador. No fueron muchas las leyes a favor del indio, aunque tampoco lo eran las disposiciones en su contra. El problema estaba en la interpretación antojadiza que las autoridades hacían a estas normas.

Caciques y gamonales movían sus poderosas influencias en las altas esferas del poder. Desde las Cámaras Legislativas y los Tribunales de Justicia, a los salones de Palacio. La 
ley no necesitó ser contraria al indígena, solo bastó con la interpretación que se hacía y según quienes aplicaban la ley. Se llevaron a cabo algunas protestas infructuosas.

\subsection{Entre los años 1902 al 1910}

En esta etapa, hubo reformas políticas favorables para el resto de la población peruana, mas no para el indígena. Para el hombre andino, continuaba entronizada una relación colonial dominante.

En esta etapa, gracias a los esfuerzos de Manuel Zúñiga Camacho, el indígena se abría por primera vez a los conceptos de propiedad privada y derechos humanos. A su vez, durante este período, se acrecentaron las protestas en las calles. La respuesta gubernamental fue violenta. Los movimientos eran neutralizados con uso de la fuerza militar. Soldados armados enfrentaron las protestas enardecidas.

\subsection{Entre los años 1911 al 1915}

Lamentablemente, para este período no se registraron cambios notables en la situación política del indígena. Por supuesto que, a estas alturas, el indígena se desarrolló de cara al progreso, pero todavía padecían los abusos de las autoridades políticas.

El gamonalismo se constituyó en un verdadero crimen organizado. Para infundir terror entre los pobladores, y ayudados de un látigo, destrozaban las carnes de los indígenas. Incendiaban sus chozas, violaban sus mujeres y les robaban.

En Lima, el presidente Augusto B. Leguía empleó al indigenismo como bandera de propaganda política; sus intereses estaban con los gamonales. Los indígenas que habían aprendido a leer y escribir, ya eran considerados como ciudadanos, previa inscripción en el registro militar. De este modo podían ser reconocidos como electores.

Por primera vez, el hombre andino tenía delante de sí, la opción de elegir a un representante netamente indígena. Estos 
sueños políticos, aún ideales, debían esperar algunos años más. El ciudadano limeño, por lo general permanecía desinformado de los excesos cometidos contras los indígenas. Los diarios de la costa callaban.

\section{Contexto educativo}

\subsection{Antes de 1902}

El aymara nunca conoció la escritura en grafemas. Con la llegada de los españoles, el idioma castellano se volvió la lengua dominante. Debido a la falta de documentación, mucha información de la cultura andina se vio perdida en el tiempo. Aunque los españoles fueron expulsados, en Perú quedaron para siempre la religión cristiana y la lengua castellana. Con dificultad, el indígena aprendió a hablar el español, pero no lo leía ni escribía.

Esta ignorancia, perpetuada por el hombre blanco, también fue aprovechada por el mestizo: para robar las tierras indígenas y cobrarles gravosos impuestos. Convenía para los intereses de los victimarios, evitar a toda costa que algún día el indígena aprenda a leer, que conozca sus derechos y así estar habilitado para defenderlos.

El sacerdote era conocedor de la lengua española, pero nunca se interesó en educar al indio. Los gobernadores y el juez de paz se coludían con él, en un cometido inhumano de desinformación e ignorancia intencionada.

\subsection{Entre los años 1902 al 1910}

El problema educativo del indígena era mucho más que un asunto pedagógico. Involucró los problemas de estado, de gobierno, de factores sociales y económicos. El indígena andino necesitaba mucho más que aprender a leer y escribir.

En este período se fomenta la creación de escuelas rurales. El dilema consistía en educar al indígena, o proteger los intereses materiales del gamonal, el terrateniente y el cura. En estas circunstancias alguien debía dar un primer paso. Así, en el año 1902, el indígena 
puneño Manuel Zúñiga Camacho fundó la primera escuelita indígena, en Utawilaya, Platería.

Con los años, la simpatía de Zúñiga Camacho a los adventistas creció hasta su bautismo. Era de esperarse la reacción de la religión dominante. Habiendo despertado los celos del clero, la escuela de Platería fue clausurada. Para ello se pretextaron omisiones administrativas.

Hubo una fuerte reacción de protesta y descontento. La escuela de Platería era muy querida por los lugareños. Como con el ayllu, la población contribuyó con su construcción y amueblamiento. Las protestas trajeron como resultado, la reanudación de la escuela y sus actividades educativas en 1908 .

\subsection{Entre los años 1911 al 1915}

En este período de la historia, el hombre andino ya sabía leer y escribir. Pero esta nueva realidad, no era la solución de sus problemas y necesidades. La lectura y escritura lo colocaban en las vías del progreso, en condiciones semejantes a las del mestizo y el blanco.

Su educación, debía asegurarle una posición favorable de progreso en la sociedad. Más que leer y escribir, el indígena debía liberarse, alejarse de sus vicios, sus atavismos; y para estos fines, lamentablemente, muchas escuelas rurales estaban condicionadas a la coerción feudal.

Este tipo de solución, no podía llegar desde adentro, se hacía necesaria una ayuda foránea. Dicho soporte llegó a través de los misioneros protestantes extranjeros. Fue Thomas Wood el pionero de la educación en Perú, en 1891. Sin embargo, sus esfuerzos no penetraron los andes sureños.

Fueron los adventistas del séptimo día quienes, según los abundantes registros históricos expuestos anteriormente, se consolidaron como los pioneros de la educación cristiana protestante de los andes puneños. 
Esta iniciativa educativa causó tal revuelo, que aún los principales críticos del protestantismo le dedicaron varias líneas descriptivas. Su impacto fue poderoso. El indígena andino recobró su amor propio, fue progresista y se mostró optimista por el futuro.

Eran centros de preparación teórica y práctica. Destacó por su énfasis integrador del desarrollo humano. Inculcaron la necesidad por las prácticas de higiene, salud física y acciones de moralidad. Como consecuencia, los indígenas abandonaron sus vicios y su apego al alcohol. Hubo un retorno al régimen vegetariano. Llama la atención del lector, que todo este aprendizaje ocurría en un ambiente feliz.

La reacción de quienes se opusieron a la educación del indígena, a través de los siglos, despertó. Hubo acusaciones de distintos tipos. Basados en el prejuicio a los extranjeros, corrieron el rumor de que los adventistas obedecían a una campaña de desnacionalización del peruano, haciéndole cada vez más norteamericano.

Los adventistas respondieron con rapidez e inteligencia. Inmediatamente empezaron a enseñar lecciones de educación cívica y patriotismo. La transparencia en el proceder de los adventistas, llevó a los indígenas a confiar en ellos. Los indios andinos amaban a los misioneros extranjeros, por ello, comenzaron a imitarles casi en cada aspecto.

Empezaron a vestir como norteamericanos, algunos cambiaron el chullo y el poncho por una camisa de vestir americana. Había que ver al nuevo indio, caminar por los poblados con cierto aire de anglosajón.

Estas escuelas recibían gran cantidad de asistentes. Cada fin de semana o feriados, las escuelas adventistas estaban abarrotadas de madres que entregaban a sus hijos a la educación protestante, con esperanzas de progreso. Mientras tanto los locales adventistas permanecían atestados, las capillas de la colonia española quedaban desoladas. 
Las sesiones de clases eran impartidas sin costo monetario, pero sí con trabajo remunerado. Ciertos historiadores ensayaron algunas explicaciones del éxito de estas escuelas adventistas, casi siempre comparándolas con los métodos impasibles de las capillas católicas. La educación adventista en los andes peruanos, fue un éxito de repercusiones sociales, religiosas y salubres impresionantes.

\section{Conclusión}

El contexto religioso, social, político y educativo del indígena andino anterior a 1902, estuvo fuertemente marcado por la conquista española. Perdieron su identidad, su posición en la sociedad, se refugiaron en los vicios de la embriaguez, fue discriminado, ultrajado, violado y en ocasiones, asesinado. Sin esperanza, yacía en un estado de penuria y descontento. La religión de los españoles no hizo sino agravar su situación, condenándole a las llamas del infierno si no se sometían de rodillas.

El indígena Manuel Zúñiga Camacho fundó una escuela en Utawilaya para conducir la mente del hombre andino hacia el conocimiento, en sus formas elementales de lectura y escritura. Tal esfuerzo fue recompensado con el escarnio y las acciones agresivas del gamonal, el terrateniente y el cura. Su situación no mejoraba, pero un sentimiento de rebeldía se arraigaba en su interior.

A todo esto, el socorro llegó de afuera del Perú. Fernando y Ana Stahl, dos norteamericanos misioneros, continuaron el trabajo educativo iniciado por Camacho. Añadieron a la enseñanza intelectual de la escuela de Utawilaya, los elementos sociales, físicos y espirituales, tan característicos de la filosofía adventista educativa. El cambio en el indígena fue radical y en poco tiempo. Se reintegró en la sociedad, recuperó su cariño hacia la vida reivindicándose después de más de cuatro siglos de opresión. 
La religión dominante no vio con buenos ojos al protestantismo misionero en el altiplano. El obispo de Puno Valentín Ampuero, encabezó el ataque a la Escuela de Platería de 1913, destruyéndola casi por completo. Este acto, llamó poderosamente la atención del senador Severiano Bezada, quien presentó un proyecto de reforma del art. 4 de la constitución política del Perú. Este cambio, permitió el ejercicio de una confesión religiosa según la conciencia de cada ciudadano.

La resistencia del catolicismo en Lima no se hizo esperar, sin embargo, los hechos fueron tan contundentes que entre los políticos peruanos casi no hubo oposición. Dos años después, en 1915, se consolidó la libertad religiosa en el Perú.

La relevancia histórica del adventismo es lo suficientemente importante, para que forme parte de la historia secular del Perú. Es un punto de quiebre en la historia del indio del altiplano, un antes y un después tan notable como la llegada de los conquistadores españoles a los Andes.

A continuación, algunas razones de esta conclusión:

1. Los adventistas, son uno de los tres primeros grupos protestantes que arribaron al Perú en el siglo de la declaración de independencia peruana y establecimiento de la República del Perú.

2. En más de cuatro siglos de opresión al indígena andino, los adventistas le tendieron la mano solidaria y tuvieron gran éxito entre ellos.

3. Los adventistas impulsaron notablemente la primera escuela indígena en la historia del Perú.

4. Los adventistas no cesaron de fundar escuelas en el altiplano, en gran mayoría de esos lugares, fueron bien recibidos. 
5. La obra de los primeros misioneros adventistas no consistió solo en enseñar al indio a leer y escribir. Se ocuparon también de su desarrollo físico, social y espiritual.

6. Hubo una mejoría considerable en el aspecto religioso, social y educativo del indígena andino, pero su situación política no mejoró. Los adventistas no mostraron tener un interés especial en el desarrollo político del altiplano. Esto señala a primera vista que, si los misioneros adventistas no hubiesen incursionado en los Andes, la realidad religiosa, social y educativa indígena, de las dos primeras décadas del siglo XX, no habría cambiado para bien. Estaríamos hablando de otra historia.

7. A raíz del ataque del obispo de Puno, Valentín Ampuero, a la obra adventista en Platería; se presentó el proyecto de reforma del art. 4 de la constitución política del perú con gran éxito. Gracias a ello, y a la obra misionera iniciada por el metodista Francisco Penzotti desde 1888, la libertad religiosa en Perú se hizo realidad el 11 de noviembre de 1915.

\section{Referencias}

Arguedas, José María. El arte popular religioso y la cultura mestiza. Lima: Editorial Cip, 1958.

- Formación de una cultura nacional indoamericana. México: Siglo XXI Editores, 1977.

- Todas las sangres. Lima: Carlos Milla Batres, 1980.

Armas Asin, Fernando. Liberales, protestantes y masones: Modernidad y tolerancia religiosa (Perú siglo XIX). Vol. 29 of Archivos de historia andina. Cusco, Lima: Centro de estudios regionales andinos Bartolomé de Las Casas; Pontificacia católica del Perú, 1998.

Barrantes, Emilio. Historia de la educación en el Perú. Lima: Mosca Azul Editores S.R.L., 1989.

Basadre, Jorge. Historia de la República del Perú. 5th ed. 6 vols. Vol. 1. Lima: Editoria Peruamérica S.A., 1963. Bouysse-Cassagne, Thérèse. La identidad aymara: Aproximación 
histórica (Siglo XV, Siglo XVI). La Paz: HISBOL-IFEA, 1987.

Bustamante y Rivero, José Luis. Una visión del Perú. Imprenta Matutina, Montevideo. 1941.

Castro Bastos, Leonidas. Geohistoria del Perú: Ensayo económico-político-social. Lima: D. Miranda, 1962.

Cerrón Palomino, Rodolfo. Lingüística aymara. Perú: Centro de Estudios Regionales Andinos "Bartolomé de las Casas", 2000 .

Chapin Hazen, Dan. "The Awakening of Puno: Government Policy and the Indian Problem in Southern Peru, 1900-1955". tesis doctoral, Yale University.

Chirinos Soto, Enrique. Historia de la República del Perú, 1821-1982. Lima: Editorial Minerva, 1982.

Choque Canqui, Roberto. La cosmovisión aymara. La Paz: UCB: Hisbol, 1992 .

- Sociedad y economía colonial en el sur andino. La Paz: HISBOL-IFEA, 1993.

Colombres, Adolfo. Por la liberación del indígena: compilación del Proyecto Marandú; documentos y testimonios. Argentina: Ediciones del Sol S.A., 1975.

Cook, Anita. Wari y Tiwanaku: entre el estilo y la imagen. Lima: Fondo Editorial PUCP, 1994.

Costa Villavicencio, Lázaro. Historia cronológica del Perú, 1700-1799. Lima: Salesiana, 1960.

Coulanges, Fustel d. La ciudad antigua. 9th ed. Vol. 75 de Biblioteca EDAF. Madrid: EDAF, 1996.

Cragnolino, Silvia. Haya de la Torre el indoamericanismo en América Latina. Buenos Aires: Centro Editor de América Latina S.A., 1984.

Cuentas, Alberto. Rumores del Titikaka. Lima: Casa Editora "La Opinión Nacional", 1929.

Descola, Jean. La vida cotidiana en el Perú en tiempos de los españoles, 1710-1820. Argentina: Librería Hachette S. S., 1964.

Drinot Piérola, Pedro Pablo. La libertad de cultos y la Acción Social Católica en el Perú. Pastoral y Conferencia del Obispo de Huánuco. Huánuco: Imprenta El Seminario, 1915.

Earl Church, George. Aborigines of South America. London: 
Chapman and Hall, 1912.

Encinas, José Antonio. Causas de la criminalidad indígnena en el Perú: Ensayo de psicología experimental. Lima: Villaran, 1919.

- La Educación, su función social en el Perú, en el problema de la nacionalización. Lima: E. Z. Casanova, 1913.

- Un ensayo de escuela nueva en el Perú. Vol. 1. Lima: Minerva, 1959.

- Un ensayo de esucela nueva en el Perú. Vol. 2. Lima: Editorial Universo, 1969.

- Educación de la raza indígena. Arequipa: Tipografía Quiroz, 1913.

- Perú indígena. Perú: Instituto Indigenista Peruano, 1952 .

- Por la libertad de pensamiento: discursos parlamentarios. Lima: Fondo Editorial del Congreso del Perú, 2013.

- Un ensayo de escuela nueva en el Perú. Lima: Minerva, 1932.

Escobar, Gabriel. La estructura política rural del departamento de Puno. Cuzco: Editorial H. G. Rozas S. A. , 1961 .

- Organización social y cultural del sur del Perú. México: Instituto indigenista interamericano, 1967.

Escobedo, R. El tributo indígena en el Perú (Siglos XVIXVII). Pamplona: Ediciones Universidad de Navarra, 1979 .

Flores, Benjamín. Monografía de la provincia de Lampa. Arequipa: Tipografía Quiroz, 1928.

Frisancho Pineda, Ignacio. Negros en el altiplano puneño. Puno: Editorial "Samuel Frisancho Pineda", 1983.

Giraldo, Santiago. Consideraciones generales para la historia del Perú. Puno: Imprenta de "La Juventud".

Gonzáles Prada, Manuel, Horas de Lucha. Lima: Editorial Universo, 1974.

- Prosa menuda. Argentina: Ediciones iman, 1941.

- Anarquía. Santiago de Chile: Ediciones Ercilla, 1936 . 
- Pájinas libres. Paris: Tipografía de Paul Dupont, 1894 . 1939

- Propaganda y ataque. Argentina: Editorial Iman,

Guerra Martinière, Margarita. Historia general del Perú: La República, 1827-1899. Lima: Editorial Brasa S. A., 1993.

- Historia General del Perú: La República, $1900-$ 1948. Lima: Editorial Brasa S. A., 1993.

Guevara Velasco, Agustin. Apuntes sobre mi patria: Volumen del departamento de Puno. Cuzco: Editorial H. G. Rozas S. A., 1954.

Guibovich Del Carpio, Lorgio. Pensamiento antropológico de Haya De La Torre. Lima: Ediciones y Distribuciones "Palma", 1988.

Guillermo Llosa, Jorge. Identidad histórica de América Latina. México: Diana, 1992.

Gutiérrez, Erancisco. Una propuesta educativa latinoamericana. Argentina: Editorial Humanitas, 1986.

Haya de la Torre, Víctor Raúl. ¿A dónde va Indoamérica? Santiago de Chile: Editorial Ercilla, 1935.

- Por la emancipación de américa latina. Buenos Aires: Triunvirato, 1927.

Herrera, Centurión. El Perú actual y las colonias extranjeras (1821-1921). Bérgamo: Istituto Italiano D'Arti Grafiche, 1924 .

Housse, Rafael Emilio. Los hijos del sol: Historia, religión, ideales y costumbres de los indios quichuas del Perú. Santiago, Chile: Empresa Editora Zig-Zag, 1946.

Huanca, Jesús. Ideología quechua - aymara. Puno: Edit. Impresiones Lucero, 2006.

Inca Garcilaso De La Vega. Comentarios reales de los incas. Vol. 1. Lima: Editorial Universo, 1609.

Kapsoli, Wilfredo. El pensamiento de la Asociación Pro Indígena. Cusco: Centro Las Casas, 1980.Kauffmann Doig, Federico, Raúl Porras Barrenechea, y Carlos D. Valcárcel. Historia general de los peruanos. 10th ed. Lima Perú: Ediciones PEISA, 1986.

Klaiber, Jeffrey. Iglesia, disctaduras y democracia en américa latina. Lima: Fondo Editorial PUCP, 1997. 
- La iglesia en el Perú. Lima: Fondo Editorial PUCP, 1987 .

- Religión y revolución en el Perú, 1824-1988. Lima: Centro de Investigación de la Universidad del Pacífico, 1988 .

Klarén, Peter F. Nación y sociedad en la historia del Perú. Vol. 36 of Estudios históricos. Lima: IEP, 2004.

Lassús Arévalo, Carlos. Los pobladores indígenas del Perú a través de la historia. Lima: Servicio de Publicaciones y Propaganda de la Comisión Central del Censo, 1939.

Lumbreras, Luis. Los orígenes de la civilización en el Perú. Lima: Editorial Milla Batres, 1981.

Mariátegui, José Carlos. 7 ensayos de interpretación de la realidad peruana. Lima: Editorial Minerva, 1928.

Martín, José Carlos. José Pardo y Barreda, el estadista: un hombre, un partido, una época. Lima: Cía. de Impresiones y Publicidad, 1948 .

Marzal, Manuel M. El rostro indio de Dios. Lima: Pontificia Universidad Católica del Perú, Fondo Editorial, 1991.

Milla Villena, Carlos. Génesis de la cultura andina. 5th ed. Lima: Wayra Katari [Carlos Milla Villena], 2008.

Money, Herbert. La libertad religiosa en el Perú. Lima: Editorial Antártida, 1965.

Montero, Carmen, La Escuela Rural, Variaciones sobre un tema. Lima: Proyecto Escuela, Ecología y Comunidad Campesina, 1990 .

Mörner, Magnus. La mezcla de razas en la historia de américa latina. Argentina: Editorial Paidos, 1969.

Oshige, Fernando. Comunidades campesinas: cambios y permanencias. Lima: Ediciones Éxodo, 1987.

Palma, Clemente. El porvenir de las razas en el Perú. Lima: Impresiones Torres Aguirre, 1897.

Pesce, Luis. Indígenas e inmigrantes. Lima: Imprenta de "La Opinión Nacional", 1906.

Prescott, Guillermo. Historia de la conquista del Perú. Buenos Aires: Ediciones Suma, 1871.

Radin, Paul. Los indios de la américa del sur. Argentina: Biblioteca Pleamar Conocimiento, 1948.

Reátegui, Félix. Etnicidad y exclusión durante el proceso de 
violencia. Lima: IDEHPUCP, 2009.

Roca, Erasmo. Por la clase indígena. Lima: Compañía de impresiones y publicidad, 1935.

Romero, Emilio. Balseros del Titicaca. Lima: Ediciones "Peruactual", 1934.

- Monografía del departamento de Puno. Lima: Torres Aguirre, 1928. 1959.

- Perú por los senderos de américa. Lima: Minerva,

Rostworowski, María. Ensayos de historia andina I. Lima: Instituto de Estudios Peruanos ediciones, 1993.

- Ensayos de historia andina II. Lima: Instituto de Estudios Peruanos ediciones, 1998.

- Historia del Tahuantinsuyu. Lima: Instituto de Estudios Peruanos ediciones, 1988.

Saavedra Mallea, Bautista. El ayllu: estudios sociológicos. Santiago, Chile: Editorial Nascimiento, 1938.

Sardón Espezúa, Víctor. Los aymaras bajo el arcoiris del tiempo y el espacio. Lima: WB Impresores-Editores, 2005 .

Sivirichi, Atilio. América indígena. Lima: Librería Peruana, 1934 .

Solc, Vaclav. Los aymaras de las islas del Titicaca. México: Instituto Indigenista Interamericano, 1969.

Tord, Luis Enrique. El indio en los ensayistas peruanos, 1848-1948. Lima: Editoriales Unidas S. A., 1978.

Torres Luna, Alfonso. El problema de la educación del aborigen peruano. Lima: Imp. "Lux" de E. L. Castro, 1940 .

- La meseta y el lago Titicaca. Lima: Talleres Gráficos del Colegio Unión, 1968. - Puno histórico, 1968.

Urbano, Henrique. Wiracocha y Ayar: Héroes y funciones en las sociedades andinas. Cusco: Centro de estudios regionales andinos Bartolomé de Las Casas, 1981.

Valcárcel, Daniel. Rebeliones indígenas. Lima: Editorial P. T. C. M., 1946.

Valcárcel, Luis E. Altiplano andino. México: Editorial 
Fournier, 1953.

1981 .

- Memorias. Lima: Instituto de Estudios Peruanos,

- Tempestad en los Andes. Lima: Editorial Universo S.A. , 1972 .

Vargas Ugarte, Rubén. Historia de la iglesia en el Perú. Lima: Imprenta Santa María, 1953.

Vásquez, Emilio. La rebelión de Juan Bustamante. Lima: Librería Editorial J. Mejía Baca, 1976.

Veres, Luis. La narrativa del indio en la revista "Amauta". Vol. 40 de Cuadernos de filología. Anejo. Valencia: Universitat de València, 2001.

Waldmann, Peter, and Ulrich Zelinsky. América Latina: Síntesis histórica, política, económica y cultural. Barcelona: Editorial Herder, 1984.

Zulen, Pedro. Recursos de defensa de la Escuela de Platería. Lima: Archivo Zulen, 1913. 